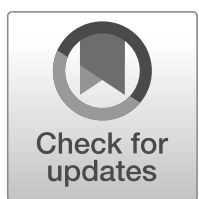

\title{
Correction to: Co-Creating Platform Governance Models Using Boundary Resources: a Case Study from Dementia Care Services
}

Babak A. Farshchian ${ }^{1} *$ [D \& Hanne Ekran Thomassen ${ }^{2}$

${ }^{* 1}$ Department of Computer Science, Norwegian University of Science and Technology (NTNU), 7491 Trondheim, Norway (Babak.Farshchian@ntnu.no); ${ }^{2}$ DIPS AS, Beddingen 10, 7014 Trondheim , Norway (het@dips.no)

The original version of this article unfortunately contained a mistake. Figures 6 and 7 have been swapped.

\section{Correction to: Computer Supported Cooperative Work}

https://doi.org/10.1007/s10606-019-09353-0

The original version of this article unfortunately contained a mistake. Figures 6 and 7 have been swapped. The correct Figures 6 and 7 are now shown here: 


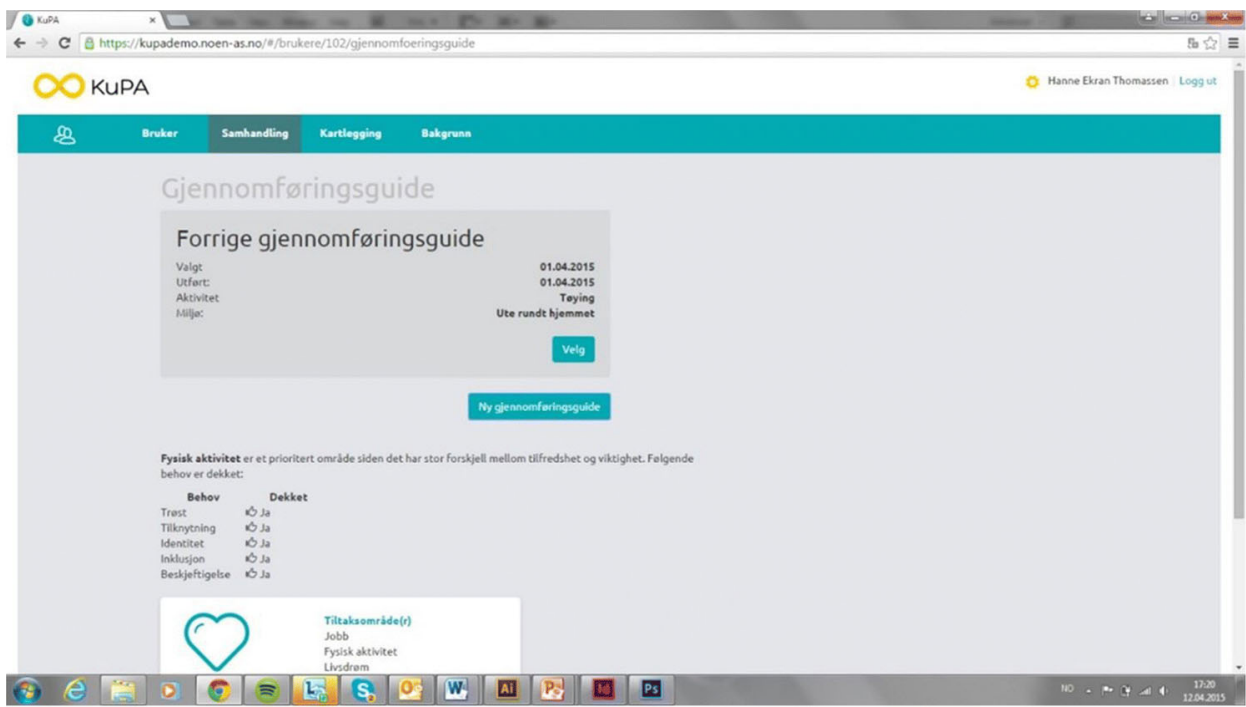

Figure 6. Activity evaluation form that is used by counselors to assess an interaction

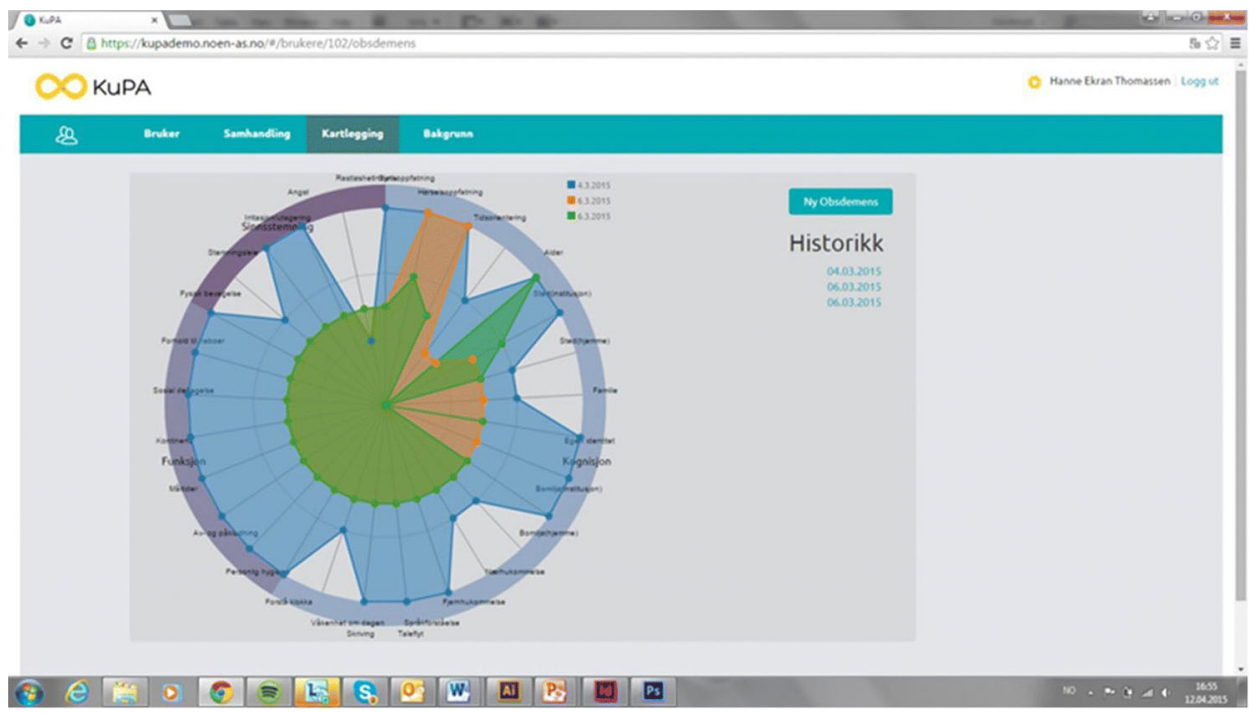

Figure 7. The OBS-demens graph that shows the latest development of a PwD related to different areas of social, physical and cognitive abilities 